\title{
END OF LIFE
}

\section{The patient who refuses nursing care}

\section{H Aveyard}

\begin{abstract}
See end of article for authors' affiliations

....................

Correspondence to: Dr H Aveyard, School of Health and Social Care, Oxford Brookes University, Academic Level 4, John Radcliffe Hospital, Headley Way, Oxford, OX3 9DU; haveyard@brookes.ac.uk
\end{abstract}

Received 5 July 2002 Revised version received 19 November 2002 Accepted for publication 28 January 2003

\begin{abstract}
Objectives: The aim of this paper is to examine the way in which nurses manage patients who refuse nursing care procedures.

Design: This paper reports on a qualitative study which was undertaken to explore the way in which nurses obtain consent prior to nursing care procedures. Focus groups were carried out to obtain background data concerning how consent is obtained. Critical incidents were collected through in depth interviews as a means of focusing on specific incidents in clinical practice.

Setting: Two teaching hospitals in England.

Participants: Purposive sample of qualified nurses.

Results: When a patient refuses nursing care, nurses respond by giving information until the patient finally accedes to the procedure. Nurses will go to great lengths to achieve patients' agreement to the procedure, but the extent to which the agreement remains voluntary cannot be ascertained by the data collected in this study. If the patient does not eventually agree to a procedure, there is evidence that nurses will administer the care in the absence of consent.

Conclusions: Nurses are concerned to obtain the patient's consent prior to the administration of nursing care but if this cannot be achieved do not regard obtaining consent as an absolute requirement. Consent is preferred, but not considered essential. Nurses have some understanding of the principles of informed consent but do not apply them to everyday clinical nursing practice.
\end{abstract}

$\mathrm{T}$ he principles of informed consent are well discussed in the ethical literature. ${ }^{12}$ Informed consent requires that a patient be informed and competent, and thereafter gives voluntary consent. ${ }^{3}$ The role of informed consent within the context of nursing care is also well established. ${ }^{3}$ The principle that a nursing care procedure cannot be undertaken without the consent of the patient is widely acknowledged..$^{5-11}$ Indeed, the United Kingdom Central Council for Nursing, Midwifery, and Health Visiting advises that all care procedures should be undertaken within a "framework of informed consent". ${ }^{12}$ It should be acknowledged, however, that there is little discussion of the application of the principles of informed consent prior to nursing care procedures in the nursing literature. Discussion is focused almost entirely on the nurse's role in facilitating consent prior to medical and research procedures. ${ }^{413}$

The lack of discussion of informed consent prior to nursing care procedures does not negate its importance. The purpose of informed consent is to protect patient autonomy. ${ }^{1}$ It therefore follows that consent should be obtained, in an appropriate manner, prior to any procedure which might be unwanted by the patient, or which might threaten his or her autonomy. Clearly many nursing care procedures have the potential to do this. It has been frequently observed that even apparently benign procedures may be unwanted by the patient. ${ }^{14}$ is Obtaining the patient's consent prior to those procedures should guard against such infringements. ${ }^{4}$

It follows that if a patient refuses care, care cannot be given. To do so would be to infringe patient autonomy and to contravene the principles of consent. It has long been established that a patient can refuse even life saving treatment. ${ }^{16}$ Indeed, the law has consistently ruled that any touching without consent is unlawful. ${ }^{3}$ It may, however, be one thing to refuse life saving treatment and another to refuse nursing care. To withhold nursing care from a patient may seem at odds with the caring disposition of the nurse. In addition, it is sometimes argued that on admission to hospital, a patient has given his or her implicit consent to basic nursing care. It has been observed that a "web of expectation" exists in health care whereby a patient tacitly agrees to the everyday procedures prior to which his or her explicit agreement is not commonly sought. ${ }^{17}$ Indeed, it is well documented that many patients are compliant recipients of health care. ${ }^{14}{ }^{18}$ There is also evidence that communication patterns on the part of staff towards patients show a tendency to promote compliance. ${ }^{19} 20$ Voluntary admission to health care services does not mean, however, that the patient is unable to withdraw and is willing to submit to all that is proposed.

It is therefore argued that although many patients do give implicit consent on admission to hospital, they retain the right to refuse even nursing care. If it is accepted that the principles of informed consent are important in nursing, then it also follows that care administered in the face of a refusal from the patient is a clear infringement of that patient's autonomy. Indeed, given the tendency for compliance, any refusal by a patient should be taken especially seriously. It is therefore argued that nurses are absolved from their duty to care if the patient (informed, voluntarily and competently) refuses that care. As a result, care, even life saving in nature, cannot be administered if the patient refuses. To do so would be to act against the principles of informed consent and constitutes unlawful touching.

In this paper, I discuss the tensions experienced by nurses when a patient refuses nursing care and the failure to adhere to the principles of informed consent. In order to do this, I refer to the findings of part of a qualitative study, undertaken as a doctoral thesis, which examined the ways in which nurses obtain informed consent prior to nursing care procedures.

\section{THE STUDY}

A qualitative study was undertaken to explore the way in which nurses obtain consent prior to nursing care procedures. The study had two main aims: 
- To examine how consent is obtained prior to nursing care procedures.

- To explore the ways in which consent could be approached by clinical nurses.

\section{METHODS}

In order to address these aims, a rich description of nursing practice was required. This description of care had to include an account or observation of how consent is obtained, in addition to nurses' interpretations of why consent is obtained as described. Six focus groups and 100 critical incidents were collected through in depth interviews. The sampling strategy was purposive, ${ }^{21}$ consisting of qualified nurses who were willing - and able-to recall and discuss critical incidents relating to consent prior to nursing care procedures, or to participate in a focus group. Ethics permission was obtained from the relevant committees in the areas where the data collection took place. All data collection took place between 1997 and 1998.

Discussion in the focus groups centred on how consent is obtained prior to nursing care procedures. The aim of the discussions was to generate background data in order to set a context for subsequent data collection. Critical incidents, collected through in depth interviews, were selected as a means of focusing on specific incidents in clinical practice in more depth. Use of critical incidents facilitated the identification of specific areas in practice in addition to providing the opportunity to explore and reconstruct the meaning of practice with the participant who described the incident.

All interviews and focus groups were tape recorded and transcribed. Transcripts were analysed using the process of constant comparison. ${ }^{22}$ Focus group and interview data were combined in the data analysis process. One major theme to emerge from the analysis was the way in which nurses manage the care of a patient who refuses nursing care. It is important to note that the competence of the patient to consent or refuse was not in question in any of the incidents included in this section. That is, given that it is suggested that competence is presumed unless there is evidence to the contrary, ${ }^{23}$ in none of the incidents related was there evidence that the patient concerned was incompetent. Incidents in which the competence of the patient to consent or refuse was in doubt are addressed in a separate paper.

\section{NURSES' USE OF INFORMATION}

When faced with a patient who is reluctant to accept nursing care, there is much evidence that nurses respond to this by giving information. Many participants gave evidence of patients who were initially reluctant to accept nursing care procedures, but who accepted the procedure once they had received further information about the proposed care. In the following incident, a patient who was reluctant to have a catheter inserted, agreed to the procedure once he had been given further information:

it was the male nurse who swayed it and.... he (the patient) initially thought that a female nurse was going to do it... I think he thought it was long term, that was the thing... after a while, he reluctantly agreed...he was uncomfortable. (interview 8)

There is evidence that this process of information giving can take some time. In a different incident, another patient was reluctant to have a catheter. The nurses respected this initially:

She didn't want the catheter putting in at all. She said "I want my daughter in here". It was the patient's wishes and we left it on that first night...the daughter came in the next day and she still wasn't particularly happy, but on the second night, we spent some time explaining that it wouldn't hurt and that we would be careful and she agreed to have it, so actually it took two nights and days... with two different shifts... to get her to have one. (interview 13)

In this incident, the nurse was adamant that a catheterisation would not be carried out until the patient agreed to it. Much effort was given to facilitating the eventual agreement of the patient to the procedure. The participant indicated, however, that had the patient ultimately not agreed to the catheter, non-catheterisation was not an option:

Eventually, yes, something could have been done, we could have got a medical team involved... but at that stage, she was going to come round eventually. (interview 13)

Here is evidence of the tension occurring when a patient refuses nursing care. On the one side, nurses are aware that care cannot be carried out without the patient's consent. There is evidence in the study that they will go to great lengths to achieve the agreement of the patient. The nurse in this incident indicated quite strongly, however, that she would not ultimately be prepared to withhold care. Withholding nursing care was not perceived to be a viable option. In this instance, the tension was resolved. Information was provided and with time, the patient finally agreed to the procedure. Whether this agreement amounts to informed consent depends on the extent to which the agreement remained voluntary and cannot be determined by the data obtained for this study.

One participant in a focus group described how information is used when a patient is reluctant to undergo a nursing care procedure:

\section{HA: Are refusals always upheld? \\ No not at all. We badger and badger. (focus group 1)}

Another group of participants said:

We abuse the power we have. We persuade patients a bit too much. We use power-well not force them but to get them to do what we want.

\section{Coax them... For someone to actually refuse they've really} got to be quite determined. (focus group 4)

Nurses meet a patient's refusal with the provision of information in order to facilitate an agreement. It is clearly appropriate to investigate the reasons why a patient is refusing a nursing care procedure, ${ }^{24}$ and to provide information where it is believed that a deficit may be contributing to the patient's reluctance to accept the care. There is clearly a line, however, between pressure to accept care that is acceptable and pressure which is not. This is discussed in the next section. Nurses in this study expressed the view that this line was often crossed. Furthermore there is an indication that nurses are not prepared to allow a patient to refuse a procedure. This is also discussed in the next section.

\section{THE USE OF PERSUASION}

The role of persuasion in situations of informed consent has been widely commented on. Many commentators argue that the health care provider has a duty not only to give information but also to persuade the recipient of care to accept the course of action considered most appropriate. They argue that the health care provider is usually in a better 
position to evaluate the different care options than the patient himself. Faden and Beauchamp argue:

\section{persuasion is a ubiquitous form of interpersonal influence that figures prominently in the consent decisions of most if not all patients... we have already stated our position (in a previous chapter) that persuasion, properly understood, poses no problem for informed consent... Indeed it is the model form of influence in informed consent contexts: it can enable and even facilitate substantially autonomous authorisations" (Faden, et al, ${ }^{2}$ p 345).}

In Faden and Beauchamp's view, not only is it permissible for a clinician to employ the use of persuasion, but it may also be a moral requirement for him or her to do so.

Frequently in clinical situations, professionals would be morally blameworthy if they did not attempt to persuade their patients to consent to interventions that are medically necessitated. Reasoned argument in defence of an option is itself information and as such is no less important in ensuring understanding than provision of acts (Faden, et $a{ }_{,}{ }^{2} \mathrm{p}$ 347).

These same sentiments are echoed by Culver and Gurt who argue that although a valid consent cannot include coercion, strong recommendations, even those which are forcefully given, are not coercive.

\section{We think that sometimes it is morally praiseworthy for a physician to put pressure on a patient during the consent process. ${ }^{25}$}

There are various reasons why persuasion might be an appropriate response to a patient who is reluctant to undergo a nursing care procedure. Many participants claimed they used persuasion when they gave information to a patient who refused a nursing care procedure. Whether they were using "persuasion", however, depends on its definition. Faden and Beauchamp define persuasion as:

the intentional and successful attempt to induce a person, through appeals to reason, to freely accept-as his or her own, the beliefs, attitudes values, intentions or actions advocated by the persuader (Faden, et al, ${ }^{2} \mathrm{p} 347$ ).

Persuasion entails that the patient "freely accept" the "beliefs, attitudes, intentions or actions" of the persuader. A patient who is persuaded still acts voluntarily. That is, persuasion, properly employed, does not undermine the principles of informed consent. The nature of the agreement remains voluntary. Persuasion cannot be used, however, to describe an interaction in which information is relentlessly given so that eventually, the patient is "bulldozed" into compliance. In this case, the voluntary nature of the agreement must be questioned. The data collected in this study does not permit identification of the exact nature of the eventual agreement between the nurse and patient. It might have been possible to make such an identification if the dialogue between the nurse and the patient been observed, or if the nature of that dialogue had been discussed with the patient. Without this information, however, there is some evidence to indicate that the patient's agreement was not freely given and that nurses' exceeded the boundaries of persuasion. Indeed, the extent to which the agreement reached was voluntary was never questioned by participants. They accepted the eventual agreement as consent and did not indicate an awareness that patients might feel compelled to comply. In addition, many expressed the view that ultimately the care procedure would have to be carried out, despite the refusal of the patient. This indicates that they were prepared to go beyond persuasion and carry out a procedure even in the absence of an agreement. In short, participants did not demonstrate an awareness that persuasion is acceptable but coercion is not. Given participants' lack of understanding and willingness to proceed even in the absence of consent, it seems likely that the influence exerted on patients could have exceeded persuasion. There is no evidence that the influence exerted on patients was limited to simple persuasion.

\section{WHEN THE PATIENT STILL DOES NOT ACCEPT CARE}

One participant described an incident in which a patient was given subcutaneous fluids despite her refusal. The patient had had a stroke and was unable to eat and drink. There was no evidence that she was unable to make her own decisions. She required additional fluids, and rehydration was considered essential. Intravenous fluids had been initiated twice. Although the patient could not speak, she was aware of the need for fluids and demonstrated her opposition to the administration of the fluids. On both occasions, the patient had protested and had pulled out the cannula.

She just shook her head because she just didn't want even the subcutaneous fluids going through, but it was really important, she wasn't taking anything orally, she was getting dehydrated, but she didn't want the needle going in. She had to have it...there was no other way. (interview 10)

In this incident, the participant did not consider respecting the refusal of the patient by withholding fluids as a viable option. Instead, the fluids were administered, in the absence of consent in the following way:

The nurse got round it by getting some (anaesthetic) cream and put it into her back so it would be harder for her to pull out and she wouldn't have to see she had a needle anyway...they used the cream so it didn't hurt. She had the subcutaneous fluids. At first she didn't want it, she's much better now. I thought it was very compassionate of the nurse, she had obviously thought it through, rather than just going ahead. I thought it was a nice individual touch to get the cream. (interview 10)

In another incident, a patient persistently pulled out her nasogastric tube. Again, withholding the tube was not considered to be an option. Again, the solution described below was to minimise the impact of the intervention by carrying it out as quickly as possible, rather than to respect the refusal of the patient:

a girl, she'd pulled out her tube, she was hardly eating or drinking...I tend to leave it for a few hours and try to explain...then do it quickly...I have put tubes down, given a bolus and taken it out again. (interview 25)

The nurses in this incident did not respect the refusal of the patient. They proceeded with nursing care because they felt it to be essential. In another incident, a patient was in great pain and unable to sit in a chair because of the backache this caused. She refused all painkillers, including those administered by intravenous infusion. The staff administered painkillers despite the patient's refusal. They were uneasy 
about this but justified their actions by appealing to principles of beneficence:

\section{It was just ridiculous to see her struggling. (interview 12)}

In a further incident, a patient refused to be catheterised. There was no evidence that the competence of the patient was in question.

Before we started, she was saying "I don't want this, leave me alone" - but she was already lying in a wet bed...(the catheter was inserted). Then she said "take it out, I don't want it in, I'm going to pull it out". I said "if you pull it out it will hurt, it's there for your comfort. She's been fine with it since, but at the time she was saying "NO! I don't want it" $^{\prime \prime}$. (interview 16)

The participant was asked whether she would do the same thing again, to which she replied:

\begin{abstract}
Yes, definitely-no question. She needed it. I think it would have been negligent not to do it. If we hadn't catheterised her, we could have managed her-her skin was already sore-we'd not been able to go to her every 10 minutes and check that she's ... I think I was doing it because I know the risks of not doing it were greater than doing it... I don't know, we needed to do it really. (interview 16)
\end{abstract}

These incidents illustrate the major theme that emerged from the data collected for this study. When a patient did not eventually agree to the administration of a nursing care procedure, the tension between respect for patient choice and the perceived duty to care could not be resolved. In these instances, nurses did what they indicated they would do in earlier incidents. They did not consider not giving care as a viable option and opted to give care, despite the patient's refusal. That is, they did not respect the principles of informed consent.

There were four incidents, however, in which nurses did respect the refusal of a patient. In each of these incidents, the care refused by the patient was considered, on reflection, not to be the most appropriate course of action. In the first incident, a patient was admitted following an attempted overdose. She refused intervention, but it was considered she would recover without assistance. In the second incident, a patient who was suffering from pneumonia refused oxygen therapy and this was respected. The participant felt that in the circumstances, it was appropriate that the oxygen be discontinued:

This man had a chest infection which had turned to pneumonia. He was very poorly and was for TLC (tender loving care)... he was kept on his oxygen and he got me during the shift and said "will you ring my family, take my oxygen off I'm going to die" ${ }^{\prime \prime}$.. and he died, it was just his oxygen that was keeping him going. It was his... he asked for that.

HA: Did you feel that it was in his best interests that the oxygen was removed?

\section{Certainly. (interview 11)}

The nurse expressed the view that had the oxygen had an expected therapeutic value, the patient's refusal would not have been respected.
HA: Might it have been more of a struggle if death had not been so imminent?

Definitely...we knew...

HA: How do you think, as nurses, we should respond if a patient says "I can't take this oxygen anymore"?

It depends on his condition...if they need the oxygen, you are going to keep it on...this gentleman was for TLC. (interview 11)

In a third incident, a dying patient refused a nasogastric tube. This refusal was upheld because there was no clear benefit to be gained from continuing the feeding. In a fourth incident, a patient's refusal of antibiotics for a severe chest infection was respected. In this incident, there is evidence that the clinicians felt that, again, it was in the patient's interests for her life not to be prolonged. The patient's refusal was clearly influential in the decision to withhold care. In the incidents in which care was withheld, however, the care was not ultimately considered to be in the best interests of the patient. There is evidence in the previous section that care considered to be essential is given in the absence of the patient's consent.

\section{LIMITATIONS OF THE STUDY}

The data obtained for this study were exploratory. It was not the specific intention to explore the management of the patient who refuses care; the topic arose as a result of inductive data analysis. In view of this, the insights gained should not be viewed as a comprehensive account. They do, however, provide information about a previously unexplored area.

\section{DISCUSSION}

Two main points arise from this study. Firstly, there is evidence that although many nurses are aware that they cannot administer care without the patient's consent, they do not consider the non-administration of care to be an option. A tension then develops. In order to resolve this tension, there is a tendency for information to be given to the patient until an "agreement" is reached. Nurses will go to great lengths to secure an agreement by the provision of information. It has been argued earlier that nurses have a moral duty to persuade by providing appropriate information. Given that persuasion entails the patient's free acceptance of the proposed care, adopting such a position is consistent with the principles of informed consent. Indeed, the provision of information has long been regarded as central to nursing practice and the benefits of information giving are well documented. ${ }^{26}{ }^{27}$ In this paper, however, there is evidence that information giving might not facilitate the free acceptance of a procedure, but might instead be coercive. In this study, nurses were not prepared to accept the refusal of the patient. They sought the patient's agreement but were determined that care should be delivered. It was observed that information was given until an "agreement" was reached. In reality, patients were not given any alternative but to accept nursing care. The extent to which the patient's eventual agreement was freely given, and not just a response to pressure from the nurse, must be questioned. There is a fine line between the use of information to persuade rather than to coerce; the application of which is beyond the scope of this paper. The lack of choice given to patients provides evidence, however, that they may have been coerced rather than persuaded into accepting care. Furthermore, none of the participants questioned the voluntary nature of the eventual 
agreement reached or recognised a difference between persuasion and other more coercive influences, a finding which fails to reassure the reader that the boundaries of the use of persuasion would not be breached. The findings of this study support those of other studies in which it was found that information is used to achieve the patient's compliance, rather than facilitate informed consent to the proposed care. An early non-nursing study, showed that parents had little real choice about the care and management of their child, despite being "involved" in the decision making. ${ }^{28}$ Communication between the professional and the parent was described as an "orchestrated encounter" in which there was a sense of fait accompli, that care would be carried out, preferably with the parents "on side". The way in which nonnursing health care professionals control the outcome of conversations with patients has been widely discussed. ${ }^{19} 20$ From a nursing perspective, it has also been suggested that information giving might constrain rather than facilitate patient choice. $^{1829}$

When detailed information was provided, this often appeared to be "coercive" - that is, it was provided in a way that encouraged patients to follow a particular decision. ${ }^{18}$

Although the data collected in this study did not allow for examination of whether the nature of the patient's agreement prior to nursing care procedures, was or was not voluntary there is no evidence that nurses use information to persuade and inform only. Indeed, the lack of choice indicates an element of coercion. Evidence from this study confirms that in the studies cited above, information was used to enforce compliance, rather than to facilitate informed consent.

Secondly, when information giving did not result in securing the patient's "agreement" prior to a nursing care procedure, nurses were unable to resolve the tension between respecting patient choice and administering care. In these incidents, the patient persisted in his or her refusal despite the best efforts of the nurse to secure an agreement. Nurses in this study defaulted to providing care, despite the patient's refusal, unless care was considered no longer appropriate. That is, care procedures were not provided within a "framework of informed consent". ${ }^{13}$ They were given outside this framework. Nurses were unhappy about doing this, but considered that failure to administer was not a viable option. This failure to respect a patient's refusal was also identified by Holm who found that health care professionals were prepared to override the refusal of a patient if harm from withholding the intervention could be expected. ${ }^{30}$

When the conflict occurs, and when the professional has decided that the harm is sufficiently significant to override the patient's wishes, various measures may be taken to "persuade" the patient to do the right thing. Information can be given selectively, the patient can be "threatened" or a decision may simply be imposed. ${ }^{30}$

There is evidence in this study that nurses do not allow a patient to refuse nursing care. Participants in this study expressed a strong preference for securing the patient's agreement prior to carrying out care. They did not feel, however, that care should be omitted if the patient's agreement could not be achieved and the intervention was clinically indicated. In their view, consent can be described as desirable but ultimately not essential.

Nurses demonstrated some knowledge of ethical principles and were concerned to incorporate these into their practice but seemed unaware how to do so when faced with a patient who refused nursing care. They were unable to apply the principles to clinical nursing practice. It has been mentioned earlier in this paper that informed consent is discussed in the nursing literature almost entirely with reference to nonnursing procedures. It is suggested that this is insufficient and that generic discussion of principles fails to equip nurses with skills they need to apply principles in everyday nursing care situations. It is therefore recommended that further work be undertaken to explore the application of the principles of informed consent and refusal to the everyday practice of nursing care.

\section{ACKNOWLEDGEMENTS}

This paper forms part of a larger study which was supported by The Society for the Furtherance of Critical Philosophy who, in association with King's College, University of London, awarded it the Morva Fordham Scholarship in Health Care Ethics (1996-1999). I am especially grateful to Professor J Wilson-Barnett, Dr Rene Saran, Dr Pat Shipley, and Sarah Edwards for their support for this work.

The paper forms part of the author's PhD for which financial support was given by the Society for the Furtherance of Critical Philosophy.

\section{REFERENCES}

1 Beauchamp T, Childress J. Principles of biomedical ethics [4th ed]. Oxford: Oxford University Press, 1994.

2 Faden R, Beauchamp T. A history and theory of informed consent. New York: Oxford University Press, 1986.

3 Department of Health. Good practice in consent. Implementation guide. London: Department of Health, 2001.

4 Aveyard $\mathrm{H}$. The requirement for consent prior to nursing care procedures. $J$ Adv Nurs 2002;37:243-9.

5 Benjamin M, Curtis J. Ethics in nursing [3rd ed]. Oxford: Oxford University Press, 1992.

6 Murphy J. Ethical dilemmas in caring for a patient refusing amputation. $\mathrm{Br} J$ Nurs 1993;2:1072-6.

7 Hunka S. The right to refuse treatment-an ethical case study. Intensive Crit Care Nurs 1993;9:82-7

8 Longo M. Facilitating acceptance of a patient's decision to stop treatment. Clin Nurse Spec 1993;7:116-20.

9 Robson R. Refusing treatment. Nurs Stand 1994;8:23.

10 McGrath P. It's ok to say no! Cancer Nurs 1995; 18:97-103.

11 Toulson S. The right to die: the dilemma for A \& E nurses. Prof Nurse 1996;11:435-6.

12 United Kingdom Central Council for Nursing, Midwifery and Health Visiting. Nursing competencies. London: United Kingdom Central Council for Nursing, Midwifery and Health Visiting, 2000.

13 Leino-Kilpi H, Valmaki $M$, Arndt $M$, et al. Patient's autonomy, privacy and informed consent. Biomedical health and research vol 40. Amsterdam: IOS Press, 2000.

14 Aveyard H. Implied consent prior to nursing care procedures. J Adv Nurs 2002;39:201-7.

15 Hopkins SM. A role for advocacy in general practice. BMJ 1999;318:819.

$16 \mathrm{R} v$ Blave [1975] 3 All ER 446.

17 Engelhardt HT. Free and informed consent, refusal of treatment and the health care team. Foundations of bioethics vol 1 [ $1 \mathrm{st}$ ed]. Oxford: Oxford University Press, 1986.

18 McCormack B. An exploration into the theoretical framework underpinning the autonomy of older people in hospital and its relationship to professiona nursing practice [PhD thesis]. Oxford: Linacre College, University of Oxford, 1998.

19 Fairclough N. Language and power. London: Longman, 1989

20 Drew P, Heritage J. Talk at work, interaction in institutional settings. Cambridge: Cambridge University Press, 1992.

21 Patton MQ. Qualitative evaluation and research methods [2nd ed]. Newbury Park: Sage, 1990.

22 Lincoln YS, Guba EG. Naturalistic inquiry. Newbury Park: Sage, 1985.

23 Buchanan AE, Brock DW. Deciding for others. The ethics of surrogate decision making. Cambridge: Cambridge University Press, 1989.

24 Wear S. The irreducibly clinical character of bioethics. J Med Philos $1991 ; 16: 53-70$.

25 Culver CM, Gurt B. Valid consent and competence. Philosophy in medicine [1st ed]. New York: Open University Press, 1982.

26 Hayward J. Information-a prescription against pain. London: RCN, 1975.

27 Wilson-Barnett J. Stress in hospital. London: Churchill Livingstone, 1979.

28 Strong PM. The ceremonial order of the clinic: parents, doctors and medical bureaucracies. London: Routledge and Kegan Paul, 1979.

29 Levy V. Protective steering: a grounded theory study of the processes by which midwives facilitate informed choices during pregnancy. J Adv Nurs 1999;29:104-12.

30 Holm S. Ethical problems in clinical practice [1 st ed]. Manchester: Manchester University Press, 1997:129. 